\title{
Automatic System for Classification of Precipitation Cells ${ }^{\#}$
}

\author{
Azzaz Nafissa*, Haddad Boualem
}

Accepted $15^{\text {th }}$ August 2014

DOI: 10.18100/ijamec.77967

\begin{abstract}
This paper presents an automatic system for classification of the precipitations cells, conceived around a graphic interface. This interface is based on the fractal geometry and particularly on fractal dimension and the fractal lacunarity. We have initially analyzed these two parameters and we showed that they can be useful as discriminating parameters. Then, we developed a graphical interface which makes possible to identify in real time the type of cells. This tool was tested on different areas from the earth and showed its efficiency whatever the studied site. This system can be used in weather radar for the improvement of the precipitations estimations and in telecommunication for the correction of the signal for the microwave links.
\end{abstract}

Keywords: Fractal Lacunarity, Fractal Dimension, Convective cells, Stratiform cells, Graphical Interface.

\section{Introduction}

Precipitations are generally considered to be two clearly distinguishable types, stratiform and convective (A. Tokey and D. A. Short; 1996). This classification of precipitation is useful in a variety of meteorological applications (N. E. Anagnostou; 2004), (M. I. Biggerstaff and Listemaa S. A.; 2000), ( M. Steiner and al; 1995). It is important in understanding cloud physics, as the two precipitation systems are characterized by different precipitation growth mechanisms (J. Gao and D. J. Stensrud; 2012), (C. Gao and al; 2006), (R. A. Houze, Jr.; 1993), and it is also important in quantitative precipitation estimation from both ground and spacebased instruments (E. N. Anagnostou, and W. F. Krajewski; 1998), (Y. Yang and al; 2013).

Stratiform precipitations fall generally from nimbostratus clouds, and are of low quantities but can persists for hours, leading to a significant rain accumulation. In the other hand, convective precipitations are caused by cumulus and cumulonimbus clouds (R. A. Houze, Jr.; 1993), (A. Tokey and D. A. Short; 1996), they are characterized by strong narrow updraft, i.e. convection, where raindrops can grow rapidly. The resulting convective rainfall is intense, relatively short in duration, and highly fluctuating (F. Tridon and al; 2010).

This paper aims to make a difference between convective and stratiform cells in radar images, using a graphical application programmed under MATLAB called interface "GUI". This approach is based on the fractal geometry and particularly on fractal dimension and fractal lacunarity.

\section{Data Base}

We considered in this study four different weather radar sites namely, Dakar (Senegal), Bordeaux (France), Melbourne (Florida, USA) and State College PA (Pennsylvania, USA).

\# This paper has been presented at the International Conference on Advanced Technology\&Sciences (ICAT'14) held in Antalya (Turkey), August 12-15, 2014.

* Corresponding Author: Email: nafissa_an1@yahoo.fr

\subsection{Region of Dakar}

Dakar is the capital of the Republic of Senegal. It is located at the western extremity of Africa, on the narrow peninsula of Cape Verde.

Being in a tropical semi-desert, Dakar has a microclimate of coastal type, influenced by the monsoon trade winds and sea. The hot wet season extends from June to October with temperatures of about $27^{\circ} \mathrm{C}$ and a peak of precipitations in August (250mm).

The radar of Dakar is installed on a tower of $30 \mathrm{~m}$ above the sea level at Yoff Airport, in the east of Dakar. Its geographical coordinates are $14^{\circ} 44^{\prime}$ North latitude and $17^{\circ} 29^{\prime}$ West longitude. It is operated by both the National Meteorological Office of Senegal and ASECNA (Association for the Safety of Air Navigation). This radar works only during storm periods. It also has a chain SANAGA. The average intensity of rainfalls varies from $300 \mathrm{~mm}$ to $1500 \mathrm{~mm}$, collected from Saint Louis to Cape Skirring (A. Nzeukou and H. Sauvageot; 2002). The technical characteristics of the weather radar of Dakar are given in Table 1.

Table 1. Technical characteristics of the weather radar of Dakar region

\begin{tabular}{cc}
\hline Technical characteristic & Value \\
\hline Diameter of antenna & $2.5 \mathrm{~m}$ \\
\hline Transmission frequency & $5.7 \mathrm{GHz}$ \\
\hline Transmission power & $250 \mathrm{Kilowatts}$ peak \\
\hline Spatial resolution & $1 \mathrm{Km} \times 1 \mathrm{Km}$ \\
\hline Pulse duration & $3 \mu \mathrm{s}$ \\
\hline Repetition sensitivity & $-110 \mathrm{dBm}$ \\
\hline Beam width to $3 \mathrm{~dB}$ & $1,6^{\circ}$ \\
\hline Antenna gain & $40 \mathrm{dBz}$ \\
\hline
\end{tabular}

\subsection{Region of Bordeaux}

The city of Bordeaux is located in the south western of France. The Bordeaux radar is located in the Bordeaux-Merignac airport, whose geographical coordinates are 44 $49^{\prime} 54^{\prime \prime}$ North latitude and $0^{\circ} 41^{\prime} 30^{\prime \prime}$ West longitude. It is one of 24 metropolitan France radars. The digital analysis of the reflectivity of 8 bits 
(SANAGA) allows processing and data storage (H. Sauvageot, G. Despaux; 1990). The radar is part of the French network (ARAMIS) managed by Météo-France. The area is almost flat. Table 2 gives the technical characteristics of the radar of Bordeaux.

Table 2. Technical characteristics of the weather radar of Bordeaux region

\begin{tabular}{cc}
\hline Technical characteristic & Value \\
\hline Type of antenna & Parabolic \\
\hline Transmission frequency & $3 \mathrm{GHz}$ \\
\hline Transmission power & 500 Kilowatts peak \\
\hline Spatial resolution & $1 \mathrm{Km} \times 1 \mathrm{Km}$ \\
\hline Pulse duration & $5 \mu \mathrm{s}$ \\
\hline Repetition frequency & $300 \mathrm{~Hz}$ \\
\hline Beam width to $3 \mathrm{~dB}$ & $1,8^{\circ}$ \\
\hline
\end{tabular}

\subsection{Region of Melbourne}

Melbourne is a city of the United States of America located on the east coast of Florida. It is situated to the east of Orlando, and south of Cape Canaveral. It has a humid subtropical climate, typical of the Gulf and South Atlantic states.

The radar used is Nexrad WSR-88D type, which works on the coherent Doppler principle. The geographical position of the radar of Melbourne is $28,109^{\circ} \mathrm{N}, 80,650^{\circ} \mathrm{W}$. It allows to observe the precipitation in the oceanic, littoral and terrestrial part (D. B. Wolff and al; 2005). The Melbourne climate is subtropical, with hot and humid summers and cool winters.

The technical characteristics of the weather radar of Melbourne are given in Table 3 .

Table 3. Technical characteristics of the weather radar of Melbourne region

\begin{tabular}{cc}
\hline Technical characteristic & Value \\
\hline Diameter of antenna & $18.5 \mathrm{~m}$ \\
\hline Maximum rotation rate & Azimuth $30^{\circ} \mathrm{s}-1$ Elevation $30^{\circ} \mathrm{s}-1$ \\
\hline Maximum acceleration & Azimuth $15^{\circ} \mathrm{s}-1$ Elevation $15^{\circ} \mathrm{s}-1$ \\
\hline mechanical limits & $-1^{\circ}$ to $+60^{\circ}$ \\
\hline Polarization & horizontal linear \\
\hline Beam width to $3 \mathrm{~dB}$ & $0.93^{\circ}($ to $2850 \mathrm{MHz})$ \\
\hline Antenna gain & $45 \mathrm{dBz}$ \\
\hline
\end{tabular}

\subsection{Region of State College}

State College is located in state of Pennsylvania in the east side of the United States of America. State College is situated at an elevation of approximately 1,200 feet $(370 \mathrm{~m})$ above sea level. It is surrounded by large tracts of farmland, and an expanse of mountains and forests. State College has a humid continental climate. Temperatures average is $-3.7^{\circ} \mathrm{C}$ in January and $21.8^{\circ} \mathrm{C}$ in July. Annual precipitation is just less than 40 inches $(1,000$ $\mathrm{mm})$, and 46.3 inches $(118 \mathrm{~cm})$ of snow a year, falls in the city. The radar used is Nexrad WSR-88D type called KCCX, which works on the coherent Doppler principle. Its technical characteristics are given in Table 4.

Table 4. Technical characteristics of the weather radar of State College region

\begin{tabular}{cc}
\hline Technical characteristic & Value \\
\hline Type of antenna & Parabolic \\
\hline Latitude position & $40^{\circ} 55^{\prime} 23^{\prime \prime} \mathrm{N}($ deg min sec $)$ \\
\hline Longitude position & $78^{\circ} 0^{\prime} 14^{\prime \prime} \mathrm{W}($ deg min sec $)$ \\
\hline Elevation & 758 meters \\
\hline Beam width to $3 \mathrm{~dB}$ & $0.93^{\circ}$ (to $\left.2850 \mathrm{MHz}\right)$ \\
\hline
\end{tabular}

\section{Theoretical Concepts}

\subsection{Fractal Dimension}

The concept of fractals was first introduced by Mandelbrot (B.B. Mandelbrot; 1983), (K. I. Kilic and R. H. Abiyev; 2011), as an indicator of surface roughness. Fractal theory has been widely applied to different scientific areas, particularly to image processing. The fractal dimension contains information about geometric structures of fractals and can also be used for nonfractals structures. It is a measure used to quantize the complexity of the geometrical objects. Many approaches were proposed for estimating fractal dimension of images. In our case, we used the Box-Counting approach (S. Lovejoy and D. Schertzer; 1990). This method is based on the recovery of the space in which the object is included in order to calculate the fractal dimension Df by a grid consisting of square (or "boxes") of side $\varepsilon$. The number $N(\varepsilon)$ represents the number of boxes which are used to pave the object. The fractal dimension Df is then defined by:

$$
D_{f}=\lim _{\varepsilon \rightarrow 0}[\ln [N(\varepsilon)] / \ln (1 / \varepsilon)]
$$

\subsection{Fractal Lacunarity}

Lacunarity is another concept introduced by Mandelbrot (B.B. Mandelbrot; 1983), in an effort to quantize the nature of gaps in texture images. It is inspiring from the Latin (lacuna) origin of the english word "lake", defines a fractal as being "lacunar", when its gaps tend to be large. If a fractal has large gaps or holes, it has high lacunarity (K. I. Kilic and R. H. Abiyev; 2011). Visually different images sometimes may have similar values for their fractal dimensions. But lacunarity estimation can help us to distinguish such images. It is a measure for spatial heterogeneity. So higher values of lacunarity implies more heterogeneity, it means that an object is more homogeneous when the lacunarity is low (K. Falconer; 1990).

There are in the literature several methods for calculating the fractal lacunarity. In our case, we use the method of Allain and Cloitre, based on the sliding box algorithm, where the lacunarity $\Lambda(\mathrm{L})$ is defined as a function of the scale $\mathrm{L}$, by (C. Allain and $\mathrm{M}$. Cloitre; 1991):

$\Lambda(L)=\left(s^{2}(L) / \bar{s}^{2}(L)\right)+1=\left(\sigma^{2} / \mu^{2}\right)+1$

Where: $\bar{s}(L)=$ the average of masses per box, noted $\mu$; $s^{2}=$ variance of masses per box, noted $\sigma^{2}$.

\section{Result and Discussion}

As an illustration, we present the results for the region of Dakar (Senegal).

(Figure.1) shows an image of convective and stratiform cells, taken from Dakar radar, in July 12, 2011, at 08h a.m. fractal dimension depending on the size. The type of cells is shown in the part "result and discussion-Fractal dimension" after having clicked on the button "cells type" 


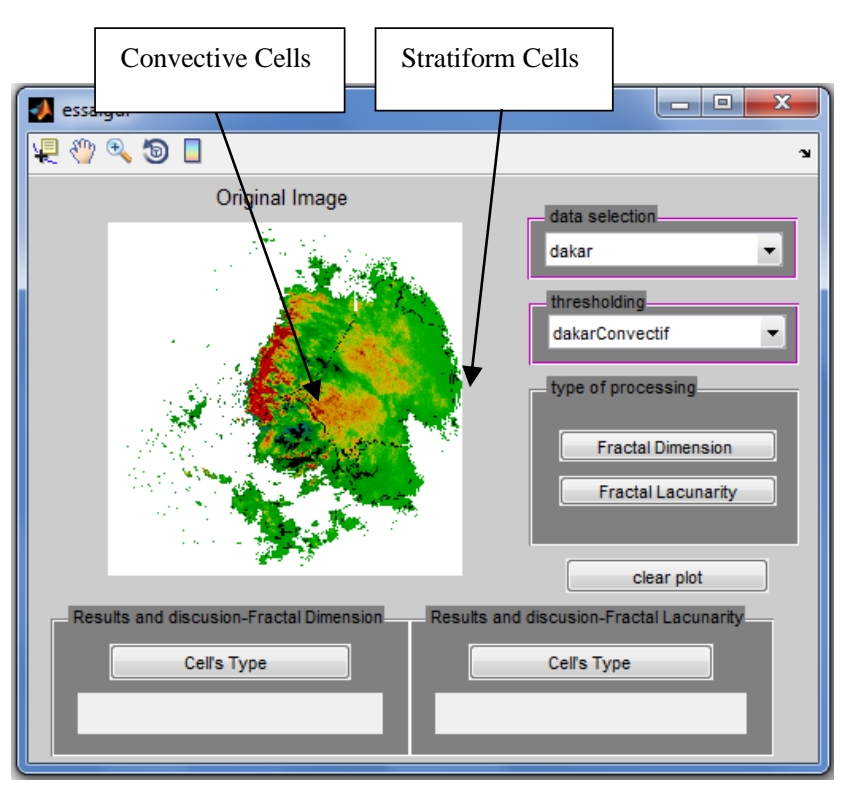

Figure 1. Convective and stratiform cells observed by Dakar radar

Primary, we select the images to be treated. If the precipitation is composed of only one type of cells, the interface makes possible to identify the precipitation type without ambiguity. On the other hand, if the two types of cells are present, we must proceed by thresholding, by clicking on one of the choices given in the menu-bar "thresholding". The choice is made depending on the type of cell we want to highlight and on the studied site.

After applying thresholding on the image presented in (Figure.1), we get the thresholded image as shown in (Figure.2). Proposed MethodologyData base

In the present work, tasks like image acquisition, preprocessing, feature extraction, classification are carried out. The classification tree is given in (Figure.3). The detailed block diagram of adopted methodology is shown in (Figure.4).

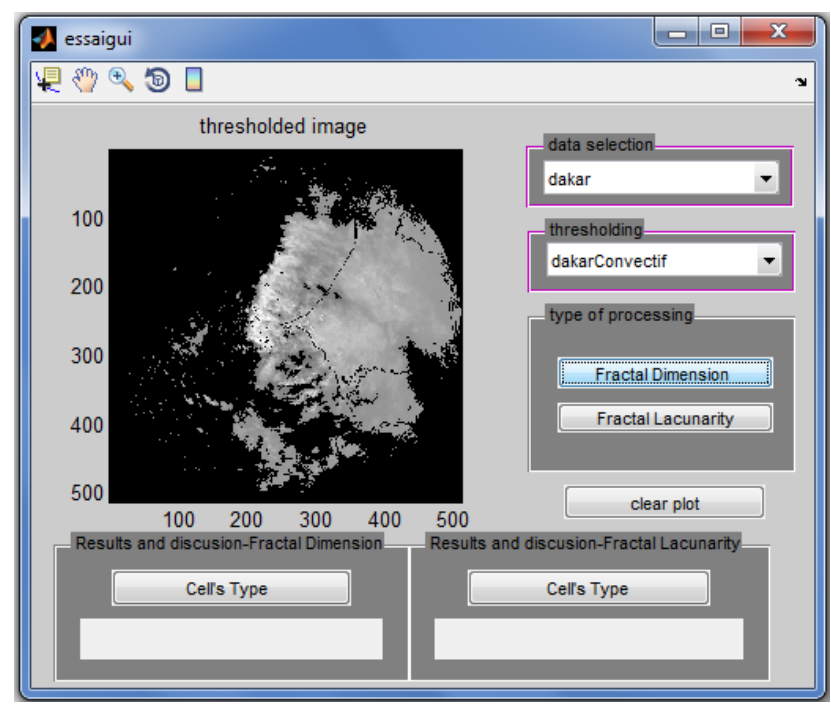

Figure 2. The thresholding images obtained from radar images in Dakar

After choosing the mode of thresholding, we will select the type of treatment we want to apply to these images. We have two types of treatments, "fractal dimension" and "fractal lacunarity." For this, we go to the frame "type of processing" and we click on the appropriate button for our choice.

\subsection{Fractal Dimension}

(Figure. $3 \& 4$ ) show that when we click on the button "Fractal Dimension", we obtain a straight curve which represents the fractal dimension depending on the size. The type of cells is shown in the part "result and discussion-Fractal dimension" after having clicked on the button "cells type".

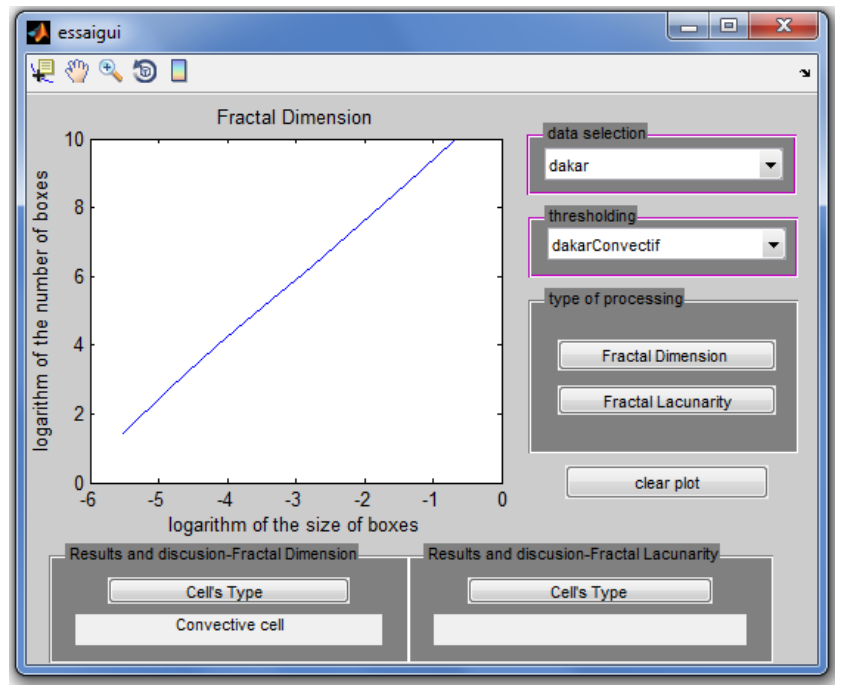

Figure 3. Fractal Dimension obtained from the convective radar cells in Dakar

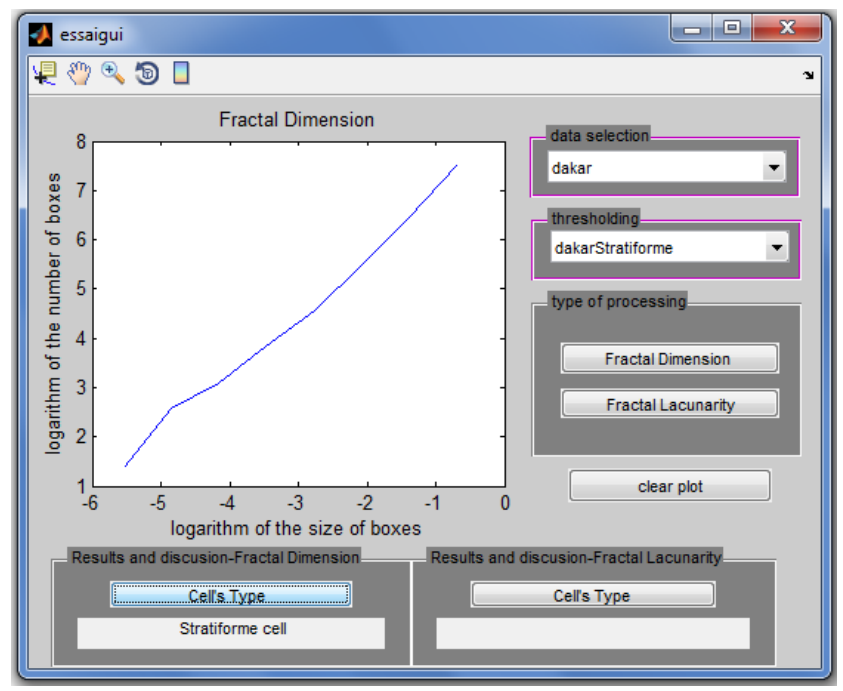

Figure 4. Fractal Dimension obtained from the stratiform radar cells in Dakar

In a previous work, we have demonstrated that the fractal dimension of the convective cells in the region of Dakar is included in the interval $[1,14 ; 1,16]$, while that of the stratiform cells is situated between 1,41 and 1,54 (N. Azzaz and B. Haddad; 2013).

The classification of precipitations in real time by our GUI using the concept of fractal dimension is based on the comparison between the fractal dimension values obtained in our process and the parameters already computed in the last work and inserted in our GUI as comparison thresholds.

The value of the fractal dimension for convective cells is still lower than that of the stratiform ones. This shows us that the stratiform cells are more deformed than the convective cells. As the fractal dimension varies with the nature of the cells and with the prevailing climate in the region considered, we conclude that the precipitations have a multifractal structure; this result is in good agreement with the literature (N. Azzaz and B. Haddad; 
2013), (D. Schertzer and S. Lovejoy; 1992).

\subsection{Fractal Lacunarity}

After clicking on the button "Fractal Lacunarity" in the part "type of processing", we obtain a power curve which represents the fractal lacunarity depending on the size.

When we click on the button "cells type" in the part "result and discussion-Fractal Lacunarity", we see the type of the cells studied as it is shown in (Figure. 5 \& 6).

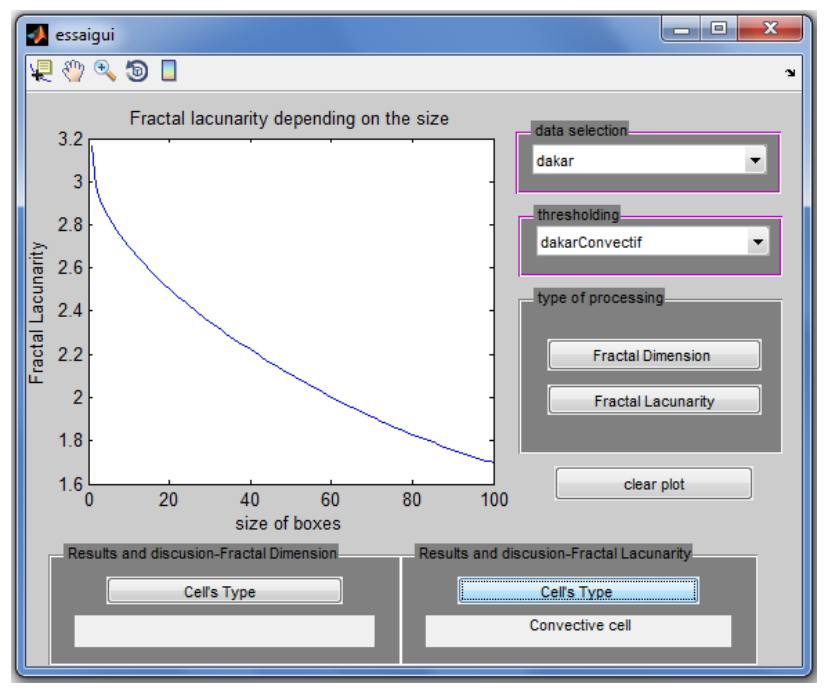

Figure 5. A curve of Fractal Lacunarity obtained from the convective radar cells in Dakar

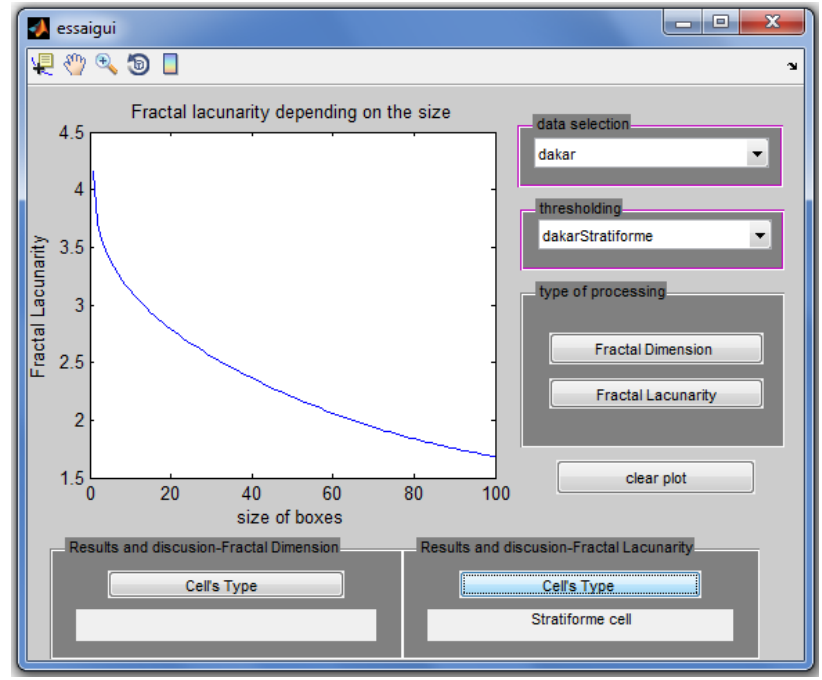

Figure 6. A curve of Fractal Lacunarity obtained from the stratiform radar cells in Dakar

It was observed in the last work that, for all analysed images, the behaviour of the lacunarity $\Lambda(\mathrm{x})$ resembles to an hyperbola $(\mathrm{N}$. Azzaz and B. Haddad; 2013). Therefore, we approached the representations by the following model function ( $\mathrm{Z}$. Annamaria; 2005): $L(x)=a \cdot x^{\wedge} b+c$.

Where:

a: Represent the concavity of the hyperbole.

$\mathrm{b}$ : Represent the order of convergence of $\mathrm{L}(\mathrm{x})$.

c: Represent the term of translation.

We found that the parameter "a" of convective cells of Dakar region varies between 489,2 and 504,1 while that of the stratiform cells is situated between 221,9 and 255,9 (N. Azzaz and B. Haddad; 2013).
To classify the precipitations in convective and stratiform cells in real time, the GUI uses the concept of fractal lacunarity on comparing values of homogeneity factors "a" obtained in our process and those calculated in the previous work and inserted in our GUI. the algorithms used in this work are implemented using MATLAB 7.0.

We now that the parameter "a" and the lacunarity value of convective cells are greater than that of stratiform ones, whatever the study region (N. Azzaz and B. Haddad; 2013). This is due to the fact that convective cells are less homogeneous than stratiform cells.

\section{Conclusion}

In conclusion, our study shows the importance of our graphical interface GUI to facilitate anyone the classification of the precipitation in two types, convective and stratiform, in real time. The GUI uses the fractal dimension and the fractal lacunarity as powerful discriminators between stratiform cells and convective cells.

This automatic system, tested on areas where prevail different climates, contributes to the improvement of the precipitations estimations through the relation Z-R for the weather radars, or to avoid the natural disasters caused especially by the violent storms. It can also be used in telecommunication for the correction of the signal attenuation for the microwave links.

This interface can be inserted without any difficulty on any weather radar.

\section{References}

[1] A. Tokey and D. A. Short (1996). Evidence from tropical raindrop Spectra of the Origin of Rain from Stratiform versus Convective Clouds. NASA Goddard Space Flight Center, Greenbelt, Maryland.

[2] N. E. Anagnostou (2004). A convective/stratiform precipitation classification algorithm for volume scanning weather radar observations. Meteorol. Appl., vol. 11, pp. 291-300.

[3] M. I. Biggerstaff and Listemaa S. A. (2000). An improved scheme for convective/stratiform echo classification using radar reflectivity. Am. Meteorol. Soc., vol. 39, pp. 2129213.

[4] M. Steiner, R. A. Jr. Houze, and S. E. Yuter (1995) Climatological characterization of three-dimensional storm structure from operational radar and rain gauge data. J. Appl. Meteorol., vol. 34.

[5] R. A. Houze, Jr. (1993). Cloud Dynamics. Academic Press.

[6] J. Gao, D. J. Stensrud (2012). Assimilation of Reflectivity Data in a Convective-Scale, Cycled 3DVAR Framework with Hydrometeor Classification. J. Atmos. Sci., vol. 69, pp. 1054-1065.

[7] C. Gao, A. Robock, S. Self, J. B. Witter, J. P. Steffenson, H. B. Clausen, M. L. Siggaard-Andersen, S. Johnsen, P. A. Mayewski, and C. Ammann (2006). The 1452 or 1453 AD Kuwae eruption signal derived from multiple ice core records: Greatest volcanic sulfate event of the past 700 years. J. Geophys. Res., vol. 111.

[8] E. N. Anagnostou, and W. F. Krajewski (1998). Calibration of the WSR-88D precipitation processing subsystem. Wea. \& Forecasting, vol. 13, pp. 396-406.

[9] Y. Yang, X. Chen, and Q. Youcun (2013). Classification of convective/stratiform echoes in radar reflectivity observations using a fuzzy logic algorithm. Journal of 
Geophysical Research Atmospheres, vol. 118, pp. 1-10.

[10] F. Tridon, J. Van Baelen and Y. Pointin (2010). Identification of Convective and Stratiform Areas towards improved precipitation estimation with a local area X-band radar. Sibiu, Romania, Advance in Radar Technology, pp. 219-225.

[11] A. Nzeukou, H. Sauvageot (2002). Distribution of Rainfall Parameters near the Coasts of France and Senegal. Journal of Applied Meteorology, vol. 41 :1, pp. 69-82.

[12] H. Sauvageot, G. Despaux (1990). SANAGA : A digital acquisition and visualization of radar data for the validity of satellite precipitation estimates, Standby climate satellite. vol. 31, pp. 51-55.

[13] D. B. Wolff, D. A. Marks, E. Amitai, D. S. Silberstein, B., L. Fisher, A. Tokay, J. Wang, and J. L. Pippitt (2005). Ground Validation for the Tropical Rainfall Measurement Mission (TRMM). J. Atmos. Ocean. Tech., vol. 31. pp. 5155.

[14] B.B. Mandelbrot (1983). The fractal geometry of nature. Freeman, W. H. Freeman and Company, New York, USA.

[15] K. I. Kilic, R. H. Abiyev (2011). Exploiting the synergy between fractal dimension and lacunarity for improved texture recognition. Signal Processing, vol. 91, pp. 23322344.

[16] S. Lovejoy and D. Schertzer (1990). Multifractals, Universality classes and satellite and radar measurement of cloud and rain fields. Journal of geophysical research, vol. 95(D3), pp. 2021- 2034.

[17] K. Falconer (1990). Fractal Geometry. Mathematical foundations and applications. John Wiley \& Sons, Chichester, England, pp. 288.

[18] C. Allain, M. Cloitre (1991). Characterizing the lacunarity of random and deterministic fractal sets. Physical Review A, vol. 44, pp. 3552-3558.

[19] N. Azzaz and B. Haddad (2013). Structure Analysis and Classification of Precipitation Cells by Fractal Geometry. Journal of Electronics, Science and Technology. vol. 12, in press.

[20] D. Schertzer and S. Lovejoy (1992). Hard and soft multifractal processes. Physical Review A, vol. 185(1-4), pp. 187-194.

[21] Z. Annamaria, R. Eleonori,, M. Pierluigi, R. Rossi, and R. Murri (2005). Medical Imaging and Osteoporosis: Fractal's Lacunarity Analysis of Trabecular Bone in MR Images. vol. 05, pp. 1063-71 